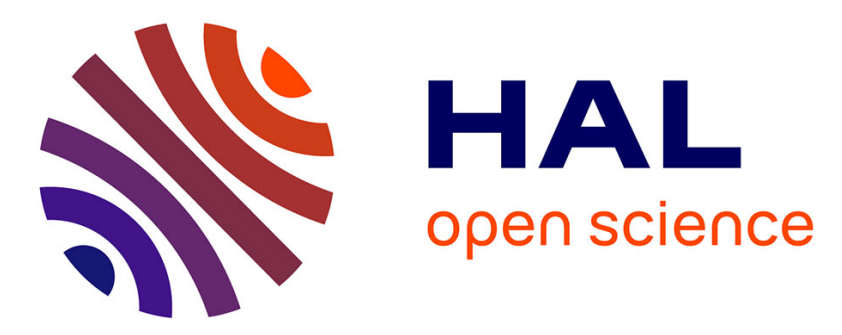

\title{
Survival in people with type 2 diabetes as a function of $\operatorname{HbA}(1 \mathrm{c})$.
}

Beverley Balkau, Dominique Simon

\section{To cite this version:}

Beverley Balkau, Dominique Simon. Survival in people with type 2 diabetes as a function of $\mathrm{HbA}(1 \mathrm{c})$.. The Lancet, 2010, 375 (9713), pp.438-40. 10.1016/S0140-6736(09)62192-9 . inserm-00457287

\section{HAL Id: inserm-00457287 https://www.hal.inserm.fr/inserm-00457287}

Submitted on 19 Mar 2010

HAL is a multi-disciplinary open access archive for the deposit and dissemination of scientific research documents, whether they are published or not. The documents may come from teaching and research institutions in France or abroad, or from public or private research centers.
L'archive ouverte pluridisciplinaire HAL, est destinée au dépôt et à la diffusion de documents scientifiques de niveau recherche, publiés ou non, émanant des établissements d'enseignement et de recherche français ou étrangers, des laboratoires publics ou privés. 


\section{Survival in people with type 2 diabetes as a function of $\mathbf{H b A}_{1 \mathrm{c}}$}

Since publication of the troubling results from the ACCORD trial ${ }^{1}$ in mid-2008, which showed that intensive treatment of type 2 diabetes was associated with a higher all-cause mortality than was conventional therapy, an explanation has been sought. The goal for people intensively treated was a glycated haemoglobin $\left(\mathrm{HbA}_{1 \mathrm{c}}\right)$ of less than $6.0 \%$. At the end of 3.5 years, when the trial was prematurely terminated, the $\mathrm{HbA}_{1 \mathrm{c}}$ achieved was $6.4 \%$ in the intensively treated and $7.5 \%$ in the conventionally treated groups; $\mathrm{HbA}_{1 \mathrm{c}}$ was $8.1 \%$ at inclusion. The most plausible explanation for these results is hypoglycaemia: the treatment target was probably too low, or glucose lowering was too rapid, or the combinations of treatments led to hypoglycaemia.

By contrast, researchers from the $\mathrm{ADVANCE}^{2}$ and $\mathrm{VADT}^{3}$ studies reported no increase in mortality in intensively treated patients. Meta-analyses of the three trials, and of the UKPDS and the PROactive trials, ${ }^{4-6}$ had sufficient power to conclude that although intensive treatment was associated with a lowered rate of major cardiovascular events and myocardial infarctions, it had no effect on mortality. Results were homogeneous between trials, but ACCORD ${ }^{1}$ was the only one that showed a significant increase in mortality. Findings from the UKPDS, ${ }^{7}$ which included younger (median age 54 years), newly diagnosed patients, showed a substantially lowered all-cause mortality and rate of myocardial infarction in the 10-year posttrial follow-up for those originally allocated to intensive therapy. This outcome suggests a legacy of early intensive treatment. In all studies, ${ }^{5}$ hypoglycaemia was more frequent in the intensively treated than in the conventionally treated group.

In The Lancet today, some light is thrown on this issue by Craig Currie and colleagues, ${ }^{8}$ with data from the large and statistically powerful General Practice Research Database, which has gathered data electronically from general practitioners in the UK. The main result in this study of 48000 patients with type 2 diabetes (cohort 1 changed from monotherapy to combination oral therapy with metformin and a sulphonylurea; cohort 2 changed to insulin treatment) is that the $10 \%$ of patients with lowest $\mathrm{HbA}_{1 \mathrm{c}}$ values $(<6.7 \%)$ had a higher death rate than all but those in the top $10 \%$, who had an $\mathrm{HbA}_{1 \mathrm{c}}$ of $9.9 \%$ or higher. Furthermore, cardiovascular disease was more frequent in this low $\mathrm{HbA}_{1 \mathrm{c}}$ group than in any other decile. Similar results were reported in the two cohorts analysed with different definitions of how $\mathrm{HbA}_{1 \mathrm{c}}$ was used in statistical analyses and after adjustment for the main covariates associated with mortality. The hypothesis that premature death might be related to hypoglycaemia is also supported by the finding that for those with an $\mathrm{HbA}_{1 \mathrm{c}}$ of less than $6.7 \%$, the insulin treated group had a higher hazard ratio (HR) for mortality $(1 \cdot 79,95 \%$ CI $1.45-2 \cdot 22)$ than did those not treated with insulin (HR 1.30, 1.07-1.58), compared with the reference decile 4 in which $\mathrm{HbA}_{1 \mathrm{c}}$ was 7.4$7.7 \%$. Furthermore, in the insulin treated, all three lower-decile groups had higher mortality than did the reference decile group, by contrast with the orally treated group, in which only the first-decile group had higher mortality. A previous study ${ }^{9}$ showed that in patients with type 2 diabetes, insulin therapy was more closely related to hypoglycaemia (odds ratio [OR] $3.44,2 \cdot 07-5 \cdot 73$ ) than sulphonylurea therapy (OR 1.54, 0.95-2.50), and low HbA $1 \mathrm{c}$ levels were also associated with any hypoglycaemia, with an OR per $1 \%$ decrease in $\mathrm{HbA}_{1 \mathrm{c}}$ of $1 \cdot 15$ $(1 \cdot 04-1 \cdot 29)$.

Causes of death were not given in Currie and colleagues' report — was sudden death a more common cause in those with low $\mathrm{HbA}_{1 c}$ ? No information is provided about the actual insulin or oral doses, or drugs used for treatment. A study ${ }^{10}$ that used the same database showed that first-generation sulphonylurea monotherapy was associated with higher mortality (HR $1 \cdot 37$, $1 \cdot 11-1 \cdot 71)$ than was second-generation sulphonylurea monotherapy (HR 1.24, 1.14-1·35) compared with metformin. Another study from the Saskatchewan Health administrative 
databases ${ }^{11}$ implicated insulin exposure with increased mortality, with a dose-response relation in patients with type 2 diabetes.

Although today's study does lend support to results of earlier studies, an epidemiological study cannot show a causal relation, and such an observational database does not provide the detailed information that is available in a randomised clinical trial, such as the frequency of hypoglycaemia. However, this study has the advantage of dealing with observations in the real world: the choice of the treating physician in prescribing specific drugs might well depend on the severity of the patient's illness and probable lifespan. Ideally, only randomised clinical trials of intensive treatment with continuous glycaemic monitoring to detect all hypoglycaemia in all groups of patients (especially in those who will die) would resolve this issue. Because this option is not feasible, careful monitoring of all hypoglycaemic events with stringent definitions, which are still under discussion, ${ }^{12}$ should be included in the trial design to assess the effect of hypoglycaemia on death and cardiovascular events. Key elements in the use of drugs that can provoke hypoglycaemia are the education of patients to recognise hypoglycaemia and systematic reporting of all hypoglycaemia. ${ }^{13}$

In patients with type 2 diabetes, when using insulin secretagogues or insulin itself, today's study does provide a rationale for an $\mathrm{HbA}_{1 \mathrm{c}}$ threshold of $7.5 \%$, corresponding to the lowest death rate and lowest event rate for large-vessel disease. Priority should be given to insulin sensitisers for as long as possible in patients with type 2 diabetes, because these drugs allow a low $\mathrm{HbA}_{1 \mathrm{c}}$ to be targeted without any risk of hypoglycaemia. More research is needed to establish $\mathrm{HbA}_{1 \mathrm{c}}$ thresholds and the combination of drugs to be recommended for intensive treatment, with perhaps differing recommendations according to the patient-intensive treatment seems to be more beneficial for cardiovascular outcomes for those who are younger than 60 years, with a short duration of diabetes, and absence of microvascular and macrovascular disease. ${ }^{5}$

*Beverley Balkau, Dominique Simon

Epidemiology of Diabetes, Obesity and Chronic Kidney Disease over the Lifecourse, CESP Centre for Research in Epidemiology and Population Health, U1018, Inserm, F-94807, Villejuif, France (BB, DS); Université Paris Sud 11, UMRS 1018, Villejuif, France (BB); and Groupe Hospitalier Pitié Salpetrière, Paris, France (DS)

beverley.balkau@inserm.fr

BB has served as a speaker for Sanofi-Aventis and on advisory panels for AstraZeneca, Bristol Myers Squibb, Lilly, and Sanofi-Aventis. DS has served as a speaker for Glaxo-Smith Kline, Sanofi-Aventis, Servier, and on advisory panels for AstraZeneca, Bristol Myers Squibb, Glaxo-Smith Kline, and Novartis.

1 The Action to Control Cardiovascular Risk in Diabetes Study Group. Effects of intensive glucose lowering in type 2 diabetes. $N$ Engl J Med 2008; 358: 2545-59.

2 The ADVANCE Collaborative Group. Intensive blood glucose control and vascular outcomes in patients with type 2 diabetes. $N$ Engl J Med 2008; 358: 2560-72.

3 Duckworth W, Abraira C, Moritz T, et al, for the VADT Investigators. Glucose control and vascular complications in veterans with type 2 diabetes. N Engl J Med 2009; 360: 129-39.

4 Ray KK, Seshasai SRK, Wijesuriya S, et al. Effect of intensive control of glucose on cardiovascular outcomes and death in patients with diabetes mellitus: a meta-analysis of randomised controlled trials. Lancet 2009; 373: 1765-72. 
5 Turnbull FM, Abraira C, Anderson RJ, et al. Intensive glucose control and macrovascular outcomes in type 2 diabetes. Diabetologia 2009; 52: 2288-98.

6 Mannucci E, Monami M, Lamanna C, et al. Prevention of cardiovascular disease through glycemic control in type 2 diabetes: a meta-analysis of randomized clinical trials. Nutr Metab Cardiovasc Dis 2009; 19: 604-12.

7 Holman RR, Paul SK, Bethel MA, et al. 10-year follow-up of intensive glucose control in type 2 diabetes. $N$ Engl J Med 2008; 359: 1577-89.

8 Currie CJ, Peters JR, Tynan A, et al. Survival as a function of $\mathrm{HbA}_{1 \mathrm{c}}$ in people with type 2 diabetes: a retrospective cohort study. Lancet 2010; published online Jan 27.

DOI:10.1016/S0140-6736(09)61969-3.

9 Miller CD, Phillips LS, Ziemer DC, et al. Hypoglycemia in patients with type 2 diabetes mellitus. Arch Intern Med 2001; 161: 1653-59.

10 Tzoulaki I, Molokhia M, Curcin V, et al. Risk of cardiovascular disease and all cause mortality among patients with type 2 diabetes prescribed oral antidiabetes drugs: retrospective cohort study using UK general practice research database. BMJ 2009; 339: b4731.

11 Gamble JM, Simpson SH, Eurich DT, Majumdar SR, Johnson JA. Insulin use and increased risk of mortality in type 2 diabetes: a cohort study. Diabetes Obes Metab 2009; published online Sept 24. DOI: 10.1111/j.1463-1326.2009.01125.x.

12 Amiel SA, Dixon T, Mann R, Jameson K. Hypoglycaemia in type 2 diabetes. Diabet Med 2008; 25: 245-54.

13 Amiel SA. Hypoglycemia: from the laboratory to the clinic. Diabetes Care 2009; 32: $1364-71$. 